\title{
Chapter 6 \\ Complicit Reproductions in the Global South: Courting World Class Universities and Global Rankings
}

\author{
Jack T. Lee and Rajani Naidoo
}

\begin{abstract}
The proliferation of global rankings has led to vigorous debates about the dominance of world-class universities and the encroaching institutional isomorphism in higher education. Specifically, the narrow metrics of rankings celebrate STEM research and institutional reputation at the expense of the humanist roots of higher education: teaching, self-cultivation, and community engagement. This critique on global rankings faces an equally vocal demand that a country must develop world-class universities in order to remain economically competitive in the global era - an instrumental logic that attracts devotees in both advanced economies as well as developing economies. Ironically, policymakers in both contexts simultaneously lament the prevalence of rankings and calibrate strategies to promote success in league tables. Although rankings attract scrutiny in both higher education policymaking and research, the implications of these metrics on higher education in the Global South receive little attention. The discourse is largely focused on top and mid ranking institutions, which are often located in the Global North. In the Global South, global rankings and the concept of world-class universities act through subtle yet powerful mechanisms to shape the contours of higher education. For many institutions and states in the Global South, the fervour is less about creating a worldclass university and more about establishing links with well ranked universities (domestically and internationally). Therefore, while the explicit goal is not to build a world-class university, policymakers are nevertheless complicit in reproducing the hegemony of global rankings. This chapter will examine the activities in which
\end{abstract}

\footnotetext{
J. T. Lee $(\bowtie)$

Moray House School of Education and Sport, University of Edinburgh, Edinburgh, UK

e-mail: Jack.Lee@ed.ac.uk

R. Naidoo

Management, Strategy and Organization Division School of Management, University of Bath, Bath, UK

Chair for Critical Studies in Higher Education Transformation, Nelson Mandela University, Port Elizabeth, South Africa

e-mail: R.Naidoo@bath.ac.uk
}

S. Rider et al. (eds.), World Class Universities, Evaluating Education:

Normative Systems and Institutional Practices,

https://doi.org/10.1007/978-981-15-7598-3_6 
global rankings exert tremendous pressure on the Global South: curriculum development, student mobility, faculty recruitment, research partnerships, and strategic planning. In mapping out the mechanisms of reproduction, the goal is to highlight the pervasive influence of global rankings and the complicity in reproduction rather than paint a binary division between the global and local dimensions of higher education.

\section{Introduction}

Over the last two decades, the discourse on world-class universities (WCUs) has permeated many domains of higher education as stakeholders attempt to define, interpret, and evaluate the apex of higher learning. This discourse transcends institutional differences and cultural contexts remarkably well to capture both the imaginations and anxieties of policymakers and institutional leaders. While some institutional leaders may lament the widespread use of ranking as an indicator of quality, many others are quick to tout their institutions' performances in the latest league tables. National policymakers may also have reservations about a global standard in assessment, yet many are eager to judge other higher education systems and foreign institutions using league tables. Similarly, higher education researchers can hardly ignore the WCU discourse despite their own misgivings about elitist higher education and the methodology of quantifying excellence. These contradictions between rhetoric and practice seldom appear in the literature on WCU, which focuses on methodological problems in ranking universities rather than the ubiquitous use of league tables to guide decision-making in planning and management.

The discourse on WCUs illustrates three broad streams of concern: clinical inquiry, practical guidance, and existential angst. Which methodology can accurately measure excellence? Have the metrics changed from last year? How can policies and strategies create and sustain world-class institutions? What constitutes a world-class university? Are we a world-class university? Does every country need a world-class university? These questions ultimately reinforce rankings as the most visible instrument in the comparison of universities worldwide. Rather than assess the quality of education, these ranking systems use proxy indicators that inflate the role of research and reputation (Hazelkorn 2017). While higher education researchers are largely critical of rankings, policymakers, institutional leaders, and students benefit from the simplicity of a league table in making sense of uncertainty (Esposito and Stark 2019). From selecting institutions for enrolment to the hiring of academics and the formation of partnerships, ranking has become the lingua franca of international higher education. In short, rankings promote an augmented reality of higher education that reduces complexity to palatable information for decision-making. Academic credentials and workplace affiliations become valuable social and cultural capital in this international competition akin to an Olympics. 
While rankings dominate many planning efforts in higher education, the reality is that most institutions in the world are preoccupied with teaching and learning. Proponents of rankings often fail to recognize that research is a privileged endeavour in higher education that remains inaccessible to many institutions around the world due to the lack of resources. Furthermore, the developmental trajectories of many higher education institutions never included research for historical and cultural reasons. For example, the venerated German universities of applied sciences (fachhochschulen) have historically worked very closely with industrial partners for the purpose of professional skills training and technology transfer rather than research. Most universities in Asia are largely teaching oriented except the rarefied national flagship institutions (e.g. Peking University and Seoul National University). While historical traditions run deep in these contexts, the tides of mimetic isomorphism are also rising as institutions pursue research to emulate leading universities around the world.

This chapter focuses on the complicated relationship between policymakers and the concept of world-class university. Specifically, the chapter examines this relationship in the context of rapidly developing higher education systems, where institutions with shorter histories and smaller international footprints often face barriers in achieving quality, visibility, and legitimacy. Many of these institutions are located in the Global South, where diverse stakeholders also demand academic credentials that can be recognized beyond the local context. The rhetoric of world-class universities affects many policy decisions in such dynamic systems. Using theoretical heuristics from two major sociologists, the discussion will highlight complicity in social reproduction. Namely, Pierre Bourdieu's insightful work on capital and reproduction and Syed Hussein Alatas' critical work on intellectual captivity provide analytical lenses for our discussion. While Bourdieu's work is widely known in the West, Alatas' work on post-colonial theory and foray into politics are well recognized throughout Southeast Asia. Alatas was also the Vice-Chancellor of the University of Malaya (1988-1991), the flagship university of Malaysia, in the later part of his career.

\section{Essentialism and Fetishism in WCU Discourse}

Given the focus in this chapter on higher education systems in the Global South, it is important to first clarify our perspectives on the relevant literature that already exists. Among the critiques of the world-class university discourse is a rebuttal against Western hegemony in education policymaking. This incisive critique builds on the growing debate about the rise of global metrics and the literature on policy borrowing in comparative education (Kamens and McNeely 2010; Rizvi and Lingard 2009; Steiner-Khamsi 2016). Some of these critiques echo the methodological and practical concerns over a global template for education as expressed by many scholars. The hegemony of rankings and its negative impact on universities in the Global South is well documented (Ordorika and Lloyd 2015). On a more 
profound level, some scholars criticize the ontological and epistemic biases in university rankings (Shahjahan et al. 2017). Namely, the Eurocentric framing of rankings enforces a narrow architecture of excellence in higher education. Ranking is also criticized as a form of soft power that hinders self-determination in non-Western higher education systems (Lo 2011). These critical reflections highlight the inequities of global metrics and the adverse consequences on higher education in the South. However, an overly homogenous view of higher education in the Global South often underpins such analyses, which rely on assumptions about culture, power, and geography. Specifically, these critiques often portray the Global North as an oppressive regime juxtaposed to a powerless Global South. Seemingly, the education landscape of the Global South is riddled with imported artefacts. From international best practices to standardized curricula, the once pristine Global South must now make sense of these artefacts. Furthermore, critical theorists often present non-Western traditions in education as innately humanistic and transformative. This binary perspective perpetuates not only stereotypes about world order but also a fetishism that romanticizes the Global South-a complete reversal of the orientalism that Edward Said chronicled in his seminal treatise (Said 1978). By framing rankings as a foreign artefact and emphasizing the impact of league tables, these critiques present power as an exogenous force, displace accountability, and exonerates local actors. We purposely avoid using the term "impact of rankings" because it maintains the spotlight on the object (rankings) rather than the subject (policymakers and policymaking). In other words, impact obviates the end user of responsibility and assumes that local agency does not exist. While indigenous knowledge and higher education institutions in developing countries are unequivocally marginalized, the Global South is far from passive in its educational development.

This chapter will examine higher education policymaking in Malaysia and Kazakhstan to illustrate the ways in which local actors perpetuate the concept of the world-class university and legitimize rankings as a global metric. Rather than focus on the intricacies of the different ranking systems, the analysis here examines the uptake and exploitation of rankings in the development of higher education.

\section{Theoretical Frameworks}

This chapter employs concepts and ideas from two eminent sociologists: Syed Hussein Alatas and Pierre Bourdieu. While the latter is well known in the West, the former is widely recognized in Southeast Asia as a public intellectual and political activist. Alatas is often considered a pioneer in Southeast Asian studies and an early advocate of multiracial unity in a diverse and fragmented Malaysia. While both scholars wrote on fundamentally different topics in different cultural contexts, both lived nearly identical years in history: Alatas (1928-2007) and Bourdieu (1930-2002). Alatas' work provides valuable heuristics on complicity in the Global South while Bourdieu's work illuminates the process of reproduction. Together, these theoretical ideas underpin the analysis of WCUs in this chapter. 


\section{Syed Hussein Alatas on Complicity}

Alatas is well known for his expositions on colonialism and intellectual captivity among Third World nations. His ideas emerged in the 1950s and crystallized in the 1970s, particularly in his seminal book The Myth of the Lazy Native (1977). He admonished colonial powers for their violence and prejudice just as influential scholars in Latin America and Africa did in the 1960s and 1970s. However, Alatas' ideas were noticeably more pragmatic and progressive than ideological. Alatas' writings do not simply condemn colonialism for all its excess and permanence, but his incisive critiques also target the elites of the Global South. He wrote extensively about intellectual captivity as a phenomenon of imitating the West without thorough consideration of local relevance and awareness of indigenous knowledge. He later called this intellectual imperialism and academic imperialism to highlight the geopolitics of conformity. Specifically, intellectual captivity relies on Western theories and methodologies and exhibits "incapacity to construct cognitive alternatives" (Alatas 2000, p. 38). "The whole phenomenon of uncritical transmission of thought can be regarded as unconscious continuation of colonialism not in the political but in the cultural sense" (Alatas 2000, p. 33). Rather than blame the colonial masters like many critical theorists of his time and social scientists of today, Alatas emphasized that intellectual captivity is self-induced. His advice for his compatriots and leaders in other developing countries was well noted for its pragmatism:

We should assimilate whatever is necessary for progress. We should be practical and independent, and at the same time tap the maximum from our own tradition. (Alatas 2000, p. 27)

These views strike a different theoretical tenor than most critical theorists because Alatas emphasized local complicity in his assessment of under development. Unlike the dependency theorists of Latin America, Alatas never advocated de-linking from former colonial powers or the absolute rejection of Western canons. His ideas on complicity are also evident in his tireless writings on corruption in developing countries: The Sociology of Corruption (1968) and The Problem of Corruption (1986). In Intellectuals in Developing Societies (1977), he demonstrates that theoretical ideas on complicity are not merely abstract constructs confined to academia; this book provides numerous empirical examples of complicity.

\section{Pierre Bourdieu on Reproduction}

In some ways it might appear strange to deploy the concepts of Pierre Bourdieu in the postcolonial contexts of the South and to use him in conjunction with Alatas. After all, we are all too aware of Bourdieu's antipathy towards Franz Fanon and Jean Paul Sartre, whom he accused of being utopian during the struggles against colonialism in Algeria (Burroway and Von Holdt 2002). But we also know that Bourdieu was horrified by the violence perpetuated by the colonisers that he 
witnessed during his fieldwork in Algeria. Bourdieu, in essence, conceptualised colonialism as a racialized system of domination, backed by naked force, which restructures social relations and creates hybrid cultures (Bourdieu 1979 [1963]). In an interesting reversal of the situation in which northern templates are projected onto the South, Bourdieu's ethnographic study of the Karbyle in Algeria provided the foundation for his theoretical framework which he then applied to France (Calhoun 2006). And similar to Alatas, Bourdieu too speaks of the complex interpenetration of the global and the local. He introduces the concept of the "cultural sabir.' The sabir is caught between "two mutually alienating universes" (Bourdieu and Sayad 2004, p. 164).

We therefore see potential in deploying Bourdieu's conceptual framework and combining this with more recent conceptualisations which draw inspiration from world systems analysis. Bourdieu's framework enables us to conceptualise universities within national and global fields of higher education (Naidoo 2004; Marginson 2008). According to Bourdieu, social formations are structured around a complex ensemble of social fields in which various forms of power circulate. The field of higher education is conceptualised as a field with a high degree of autonomy in that it generates its own organisational culture consisting of values and behavioural imperatives that were traditionally relatively independent from forces emerging from the economic and political fields (Bourdieu 1988). The activities in the field of higher education have traditionally revolved around the acquisition and development of scientific capital (Bourdieu 1986), which may be defined as particular resources that are invested with value and through which individuals and institutions are located in hierarchical order (Bourdieu 1996). As Enders (2015) has noted, rankings are so powerful in higher education because many ranking classifications echo and re-valorize significant components of scientific capital. While fields of higher education enjoy a relative degree of autonomy, these are at the same time heavily influenced by national and global fields of power within which macro actors such as the state, powerful international organisations and multi-national corporations struggle over the principles of legitimacy and power over societies. Drawing on the above conceptualisations, we argue that the strategies of higher education leaders in the South must be understood not merely within an analysis of relations within national and global fields of higher education but also in the context of wider economic, political and social power relations constituting the world system. The earlier work (for example Wallerstein 1974; Amin 1976) which theorised core and periphery relations between countries has been criticised for being static and overdeterministic. However, more recent work taking inspiration from world systems theory links agency, resistance and multi-scalar power struggles to the relationships between different cores and variegated peripheries (see, for example, Bouziane, Harders, and Hoffmann 2013). Revolving around the axes of relationality, hierarchy and power, the theoretical framework of Bourdieu combined with recent emanations of world systems theory can be seen to work together productively to provide a greater understanding of Southern complicity in global ranking. In the next sections, we introduce the empirical cases of Malaysia and Kazakhstan. 


\section{Comparative Case Studies}

Several factors inform the methodological decision to compare Malaysia and Kazakhstan in this chapter. Although categorized as upper middle income countries today, both Malaysia and Kazakhstan may nevertheless be classified as semiperipheral and former colonies, which are particularly apposite to our research focus. Both countries are extremely active in developing their higher education and promoting global engagement across many policy sectors (e.g. education, trade, and finance). Recently, Malaysia's Minister of Higher Education touted its higher education as "the most re-designed system in the world", following multiple waves of reforms dating back to the 1980s (Academic Affairs 2018). Similarly, Kazakhstan's higher education system has weathered through a series of reforms after the country gained independence in 1991 (Kovaleva and Lee 2016). Both countries also share a long history as former colonies. British and Russian conquests of Malaysia and Kazakhstan, respectively, date back to the eighteenth century. In the twentieth century, both territories gained independence and reaped tremendous benefits from the export of natural resources as rentier states (Franke et al. 2009; Varkkey 2014). Today, both Malaysia and Kazakhstan are classified as upper middle-income economies based on the World Bank's economic indices. Both countries also struggle to transform from rentier states to knowledge economies. Based on these uncanny similarities in history and political economy, this chapter draws comparisons between the two countries to illustrate local agency in the reproduction of worldclass universities. Table 6.1 provides some indicators for comparative purposes.

\section{Malaysia}

Malaysia's higher education system has expanded dramatically since the Parliament passed the Private Higher Educational Institutions Act in 1996. While private institutions have made tremendous inroads in quality and innovative program offerings over the last decade, established public universities still dominate the country's higher education system. Malaysia has pursued a few national level initiatives to cultivate world-class universities. In 2006, the government identified five

Table 6.1 Indicators for comparative purposes

\begin{tabular}{|c|c|c|c|c|c|c|}
\hline & $\begin{array}{l}\text { GDP } \\
\text { per } \\
\text { capita }^{a}\end{array}$ & $\begin{array}{l}\text { Population } \\
\text { (million) }\end{array}$ & $\begin{array}{l}\mathrm{HE} \\
\text { participation } \\
\text { rate }\end{array}$ & $\begin{array}{l}\# \text { of } \\
\text { public } \\
\text { HEIs out } \\
\text { of total } \\
\text { HEIs }\end{array}$ & $\begin{array}{l}\text { \# of } \\
\text { designated } \\
\text { research } \\
\text { universities }\end{array}$ & $\begin{array}{l}\text { Education } \\
\text { expenditure as } \\
\% \text { of GDP }\end{array}$ \\
\hline Malaysia & $\$ 9900$ & 32 & $42 \%$ & $20 / 148$ & 5 & $4.7 \%$ \\
\hline Kazakhstan & $\$ 8800$ & 18 & $50 \%$ & $61 / 131$ & 2 & $2.9 \%$ \\
\hline
\end{tabular}

${ }^{a}$ USD in 2017 participation rates from: http://uis.unesco.org/en/country/my, http://uis.unesco.org/ en/country/kz 
universities as research universities under the Malaysian Research Universities (MRU) program. Specifically, this policy aimed to place one Malaysian university among the top 50 in the world while the remaining four would rank in the top 100 (MOHE 2007; Sirat 2013). In 2008, under the Accelerated Program for Excellence (APEX), the government vetted several universities and decided to invest further in the Universiti Sains Malaysia (USM) as the leading institution in the country with the potential to attain international stature. Notably, USM's winning strategic plan for attaining excellence included a specific focus on environmental sustainability and service to the "bottom billions" in the world. Ultimately, these national policies toward building WCUs utilized preferential funding schemes, competitive student admission, infrastructure construction, and the commercialization of research to move designated universities up in rankings. While the outcomes of these bold initiatives are debatable, success in the league tables have not materialized as sought by policymakers. In fact, the designated research universities have dropped in rankings over the years. Today, the highest ranked Malaysian university is the University of Malaya, ranked in the 300-400 range by both Times Higher Education and ARWU. Established in 1905, it is also the oldest university in the country.

\section{Kazakhstan}

Kazakhstan's higher education system has experienced tremendous growth since the country gained independence from the Soviet Union in 1991. Similar to Malaysia, private higher education expanded dramatically to meet both the demographic demands of a growing population and the aspirations for a knowledge economy. A new law in 1993 allowed the establishment of private higher education institutions. While no clear taxonomy exists for higher education in Kazakhstan, the government has cultivated two national universities, several regional universities ("state universities"), and a high-profile international university established in 2010 (Nazarbayev University). The Ministry of Education and Science has recently conferred the status "research university" to Nazarbayev University, the only institution in the country with this official designation. Overall, these public institutions dominate the higher education system. The oldest institution, Al-Farabi Kazakh National University, established in 1934, is also the highest ranked (800-1000 range by Times Higher Education). In 2019, Nazarbayev University decided not to participate in global rankings until 2030, despite its strong research orientation and prominent international partnerships. The university leadership worries that the institution could be typecast as an inferior institution during its early stage of development without all the comparable metrics of a WCU (Nazarbayev University 2018). Overall, the current drive toward WCUs in Kazakhstan is heavily focused on Nazarbayev University as the higher education system undergoes systemic reforms to increase institutional autonomy and financial independence.

Several areas of higher education policymaking in Malaysia and Kazakhstan illustrate local agency in reproducing the WCU concept and affiliated ranking 
systems. The next section briefly describes these examples to provide empirical evidence for our theoretical discussions.

\section{Selecting Strategic Partners}

Many higher education institutions have strategic international partners that benefit from deep collaborations over several years. These strategic partnerships receive greater resources and publicity compared to smaller scale partnerships that emerge organically among individual academics with shared interests. In Kazakhstan, the leading national universities are keen to choose partners that rank highly in league tables. For example, the country's leading university, Nazarbayev University, touts strategic partners that include Cambridge, University of Wisconsin-Madison, University of Pennsylvania, and the National University of Singapore. Partnership activities include academic program development, external quality assurance, student exchanges, joint research, and the screening of potential new faculty members. While subject expertise is essential to sustain these partnerships, the institutional profiles of the partners (i.e. their positions on league tables) played an influential role in early discussions of creating Nazarbayev University. The international reputations of these institutions also influence the renewal of partnership contracts. Similarly, another leading university in the country, the Kazakh-British Technical University, touts a prominent partnership with the University of London rather than lower ranked institutions in the UK. In the case of Malaysia, the large private higher education sector provides many transnational education (TNE) programs. Whether it is a twinning degree or a franchised degree program, the stature of the foreign partner is critical in gaining the trust of students, parents, employers, and investors. Foreign providers such as Nottingham, Southampton, and Monash operate their own branch campuses in Malaysia. While the TNE competition in Malaysia is fierce, policymakers and institutional leaders do accord more cultural capital to a modestly ranked foreign university than it enjoys in its home country, thus reflecting Malaysia's status in both the global field of higher education as well as its semiperipheral status in the global geopolitical system. This inflation of cultural capital is pervasive in the Global South as local institutions seek legitimacy and visibility. In many discussions, "an appropriate partner" is more about the ranking position of an institution rather than a compatibility of academic interests or institutional needs.

\section{Developing Curriculum and Assessing Students}

Another area of reproducing the WCU discourse is curriculum development and the subsequent assessment of student learning. What is considered legitimate knowledge? Who can offer it? How do we properly assess student performance? In Kazakhstan, the curricula developed by well-ranked foreign universities receive 
great fanfare. Cambridge, Warwick, and University College London have all played an active role in creating curricula and assessment tools for Kazakhstan's higher education system. Cambridge Assessment is active in the systemic reform of student assessment in Kazakhstan. Specifically, Cambridge Assessment is working with an elite network of government funded schools and Nazarbayev University to reform the assessment of secondary students for entry into higher education. In higher education, the strong legacy of Soviet influence means programs and curricula are modelled after Russian examples. However, a growing movement in adopting European models is also evident in Kazakhstan's participation in the Bologna Process. Institutions such as the Institute Sorbonne-Kazakhstan and German Kazakh University also rely on flying faculty to deliver curricula developed by European scholars. Malaysia's large private higher education sector is also renowned for its import of foreign curricula in the forms of franchised and twinning degree programs. While there is a movement to supplement foreign curricula with local content, the attraction of a foreign degree program delivered in Malaysia remains quite strong.

\section{Sending Students Abroad}

The world-class university discourse also plays an influential role when Malaysia and Kazakhstan select foreign institutions for study abroad experiences. The most prominent example is Kazakhstan's Bolashak program, a prestigious national scholarship scheme that fully funds students to pursue degrees overseas. This program began in 1993, soon after the country gained independence. Today, the Bolashak program stipulates that recipients can only study in a university that is ranked in the top 100 in the world, with further specifications for subject areas based on subject rankings. Given this restriction, applicants have been known to prioritize institutional status over subject expertise or personal interests when selecting a place and program to study. On a smaller scale, the selection of institutions for semesters abroad or internships abroad also have restrictions based on league tables. National and institutional funding schemes are hesitant to support students who might have found a welcoming foreign institution that is not well ranked. Yet, these welcoming institutions may have the resources to properly host visiting students for academic studies, research experiences, and cultural immersion.

\section{Evaluating Senior Leaders and Academics}

Using world-class university rankings to inform decisions on human resource management is another example of complicit reproduction. When vetting new faculty members and academic leaders, a candidate's institutional affiliation and academic credentials may play an outsized role in hiring. Individuals with pedigrees from 
highly ranked universities in the world are commonly found in the national universities of Malaysia and Kazakhstan. Malaysia's Ministry of Education even uses rankings as one of the key performance indicators (KPIs) when evaluating its Minister of Education and state appointed university vice chancellors. This approach to personnel management trickles down to institutions' evaluations of deans. In fact, in 2006, Malaysia's flagship university, University of Malaya, sacked its vicechancellor (Datuk Dr. Hashim Yaacob) after the university tumbled 80 places in rankings over the course of 1 year from 89th to 169th in the Times Higher Education-QS league table. This sharp drop was apparently due to incorrect data submission that counted local ethnic Chinese and Indian students as "international students", thereby inflating the university's score as the 89th university in the world (Usher 2017). While the media focused on the alarming drop in ranking and the public demanded the resignation of the vice-chancellor, this incident begs us to ask broader systemic questions: Why are policymakers setting unrealistic expectations of overnight success in league tables? How did narrow global metrics of the worldclass university become a KPI of senior leadership in a higher education system? Surely the performance of any university over 1 year cannot be accurately captured through its performance in rankings (negatively or positively).

\section{Discussion}

These empirical examples from Malaysia and Kazakhstan illustrate the power of the WCU concept and the complicit reproduction of rankings as an instrument of governance. While the examples have singled out Malaysia and Kazakhstan, they are certainly not alone in the Global South when it comes to building and courting world-class universities. Many other countries engage in similar policymaking that maps out a national agenda for WCUs while neglecting important developments at lower ranked institutions. This obsession with WCUs has several critical implications for higher education systems in the Global South.

The first clear implication is mimetic isomorphism as institutions imitate the leading universities in the world based on rankings. Aspiring institutions internalize these global metrics of excellence and begin to pursue strategies that will accrue tangible points for rankings. While this trend is also evident in the Global North, institutions in the Global South with shorter histories and smaller international footprints are more susceptible to this global pressure of mimicry for the sake of legitimacy and visibility. An example of this mimicry is the premature creation of technology transfer offices and commercialization units on campuses before a university is fully prepared to engage in research (i.e. putting in place an administrative system to support research and secure grants). This type of mimicry also favors STEM disciplines while marginalizing social science and the humanities. Indigenous models of higher education such as the normal universities in East Asia with roots in education as a discipline (e.g. Beijing Normal University) and the indigenous universities in Mexico with strong ties to local communities are neglected in the 
pursuit of WCUs. These trends toward research and STEM are not necessarily helpful for developing countries or middle-income countries that require a diverse set of competencies and skills in the workforce to support economic growth. An advanced economy may be able to afford a narrow specialization in competencies while outsourcing labor, but this is a privileged path that is not accessible by many countries in the Global South. Interestingly, several advanced Western economies do not have top-ranking universities in league tables, yet they excel in research and produce leading scholars: Germany, Japan, and the Nordic countries.

Another clear implication of the pursuit of WCUs is the resource imbalance that an elitist form of higher education demands. Most countries in the Global South struggle with funding for higher education. If a country pursues a national agenda to build world-class universities, it must make difficult decisions to siphon resources away from other institutions in order to cultivate one or more promising beacons (Naidoo and Ranchod 2018). This strategy results in severe discrepancies in resources across a higher education system and generates resentment toward the elite institution(s). Interestingly, while many higher education systems in the West are confronting their shortcomings by widening participation and contributions towards social mobility (at least at the level of policy pronouncements), many governments and institutions in the Global South are chasing an elitist form of higher education based on rankings.

Another serious implication of the pursuit of WCUs is system fragmentation. As higher education institutions increasingly seek international partners for academic programs and research, local collaborations may suffer in this race toward internationalization. Several ranking systems reward institutions for the pursuit of internationalization. Where does this leave local collaborations that do not generate as much fanfare? For many institutions in the Global South, local partners are more accessible than offshore partners. As institutions continually seek international linkages, the center of gravity of a higher education system can become displaced and detached from local realities.

In essence, politicking and coercion by the Global North are insufficient to sustain the power and resilience of the world-class university discourse. Rather, key actors in the Global South are complicit in reproducing the oppressive hierarchy of global rankings. In theory, ranking discourses and practices within the national contexts of Malaysia and Kazakhstan could be recontextualised in at least three different ways. First, core ranking discourses can be simply appropriated by a cosmopolitan elite of government and higher education. Second, such appropriation can occur with major principles of hierarchy intact but with slight modifications to fit the Southern context. Third, ranking discourses can be rejected in favour of principles of subversion which are positioned as local and authentic. In the two cases that we have examined, our explanation for the extreme engagement of Southern elites with global rankings can be grounded in Bourdieu's concept of illusio, which is a visceral belief in the stakes of the game that translates into an inability to question its underlying principles, even when it reproduces disadvantage for the player (Bourdieu and Wacquant 1992). So illusio is at the same time an investment in the 
ranking game, an institutionalized interest and a principle of perception through which high status, well-resourced universities in the Global South are intimately connected to the global power nodes of higher education. Thus, exonerating policymakers and institutional leaders in the Global South from the architecture of this hierarchy creates an artificial vacuum in the discourse of world-class universities.

It is also crucial to point out that ranking systems are not entirely a Western creation as several scholars often admonish. One of the most prominent ranking systems in the world was created by Shanghai Jiao Tong University in China: the Academic Ranking of World Universities (ARWU). A few other countries in Asia have also created national and international ranking systems for universities (e.g. Taiwan and Japan). Assertions that ranking systems are Western instruments of domination conveniently ignore the role of Chinese researchers in making ARWU a global instrument since 2003.

Syed Alatas' pragmatic advice for development is highly germane as the concluding remarks for this chapter. Alatas argued, "I am not suggesting that we should close our minds to genuine knowledge from any part of the world. We should assimilate as much as possible from all sources, from all parts of the world, all useful knowledge" (Alatas 2000, p. 27). In this perspective, Alatas takes an inclusive approach to synthesize knowledge from different cultural and ontological traditions rather than rely on essentialist tropes that reinforce a divisive world order. For the advancement of scholarship, Alatas further argues that "We have to avoid assessing ourselves in terms of foreign yardsticks" (Alatas 2000, p. 31). Metrics for a worldclass university represent such perverse yardsticks. Ultimately, the challenge of development is less about a binary world order than about self-determination:

The emancipation of the mind from the shackles of intellectual imperialism is the major condition for the development of a creative and autonomous social science tradition in developing societies. (Alatas 2000, p. 44)

\section{References}

Academic Affairs. (2018). UMT home to national higher education carnival 2018 zone 9. Terengganu: Universiti Malaysia Terengganu.

Alatas, S. H. (2000). Intellectual imperialism: Definition, traits, and problems. Southeast Asian Journal of Social Science, 28(1), 23-45.

Amin, S. (1976). Unequal development: An essay on the social formations of peripheral capitalism. New York/London: Monthly Review Press.

Bourdieu, P. (1979[1963]). Algeria 1960. Cambridge, UK: Cambridge University Press.

Bourdieu, P. (1986). The forms of capital. In G. R. Richardson (Ed.), Handbook of theory and research for the sociology of education. New York: Greenwood Press.

Bourdieu, P. (1988). Homo academicus. Cambridge: Polity Press.

Bourdieu, P. (1996). The state nobility. Cambridge: Polity Press.

Bourdieu, P., \& Sayad, A. (2004). Colonial rule and cultural sabir. Ethnography, 5(4), 445-86.

Bourdieu, P., \& Wacquant, L. J. D. (1992). An invitation to reflexive sociology. Cambridge: Polity Press. 
Bouziane, M., Harders, C., \& Hoffmann, A. (Eds.). (2013). Local politics and contemporary transformations in the Arab world: Governance beyond the centre. Basingstoke: Palgrave Macmillan.

Burawoy, M., \& von Holdt, K. (2002). Conversations with Bourdieu: The Johannesburg moment. Wits University Press. Project MUSE.

Calhoun, C. (2006). Pierre Bourdieu and social transformation: Lessons from Algeria. Development and Change, 37(6), 1403-1415.

Enders, J. (2015). The academic arms race: International rankings and global competition for world-class universities. In A. W. Pettigrew, E. Cornuel, \& U. Hommel (Eds.), The institutional development of business schools (pp. 155-175). Oxford: Oxford University Press.

Esposito, E., \& Stark, D. (2019). What's observed in a rating? Rankings as orientation in the face of uncertainty. Theory, Culture \& Society, O(0), 1-24.

Franke, A., Gawrich, A., \& Alakbarov, G. (2009). Kazakhstan and Azerbaijan as post-Soviet rentier states: Resource incomes and autocracy as a double 'curse' in post-Soviet regimes. EuropeAsia Studies, 61(1), 109-140.

Hazelkorn, E. (2017). Global rankings and the geopolitics of higher education. New York: Routledge.

Kamens, D. H., \& McNeely, C. L. (2010). Globalisation and the growth of international educational testing and national assessment. Comparative Education Review, 54(1), 5-25.

Kovaleva, L., \& Lee, J. T. (2016). Higher education in Kazakhstan. In The Palgrave handbook of Asia Pacific higher education (pp. 653-663). New York: Palgrave Macmillan US. https://doi. org/10.1057/978-1-137-4.

Lo, W. Y. W. (2011). Soft power, university rankings and knowledge production: Distinctions between hegemony and self-determination in higher education. Comparative Education, 47(2), 209-222.

Marginson, S. (2008). Global field and global imagining: Bourdieu and worldwide higher education. British Journal of Sociology of Education, 29(3), 303-315.

Ministry of Higher Education (MOHE). (2007). National higher education strategic plan 2007-2020. Putrajaya, Malaysia: Ministry of Higher Education.

Naidoo, R. (2004). Fields and institutional strategy: Bourdieu on the relationship between higher education, inequality and society. British Journal of Sociology of Education, 25(4), 457-471.

Naidoo, R., \& Ranchod, R. (2018). Transformation, the state and higher education: Towards a developmental system of higher education in South Africa. In P. Ashwin \& J. M. Case (Eds.), Pathways to the public good: Access, experiences and outcomes of South African undergraduate education. African Minds: Cape Town.

Ordorika, I., \& Lloyd, M. (2015). International rankings and the contest for university hegemony. Journal of Education Policy, 30(3), 385-405.

Rizvi, F., \& Lingard, B. (2009). Globalizing education policy. London: Routledge.

Said, E. (1978). Orientalism. London: Routledge.

Shahjahan, R. A., Blanco Ramirez, G., \& Andreotti, V. d. O. (2017). Attempting to imagine the unimaginable: A decolonial reading of global university rankings. Comparative Education Review, 61(S1), S51-S73. https://doi.org/10.1086/690457.

Sirat, M. (2013). Malaysia's world-class university ambition: An assessment. In J. C. Shin \& B. M. Kehm (Eds.), Institutionalization of world-class university in global competition (pp. 205-223). Dordrecht: Springer. https://doi.org/10.1007/978-94-007-4975-7_12.

Steiner-Khamsi, G. (2016). New directions in policy borrowing research. Asia Pacific Education Review, 17(3), 381-390.

Usher, A. (2017). A short global history of rankings. In E. Hazelkorn (Ed.), Global rankings and the geopolitics of higher education (pp. 23-53). New York: Routledge.

Varkkey, H. (2014). Natural resource extraction and political dependency: Malaysia as a rentier state. In M. L. Weiss (Ed.), Routledge handbook of contemporary Malaysia (pp. 189-199). Routledge. https://doi.org/10.4324/9781315756240-18.

Wallerstein, I. M. (1974). The modern world-system. New York: Academic. 
Open Access This chapter is licensed under the terms of the Creative Commons Attribution 4.0 International License (http://creativecommons.org/licenses/by/4.0/), which permits use, sharing, adaptation, distribution and reproduction in any medium or format, as long as you give appropriate credit to the original author(s) and the source, provide a link to the Creative Commons license and indicate if changes were made.

The images or other third party material in this chapter are included in the chapter's Creative Commons license, unless indicated otherwise in a credit line to the material. If material is not included in the chapter's Creative Commons license and your intended use is not permitted by statutory regulation or exceeds the permitted use, you will need to obtain permission directly from the copyright holder. 